\title{
Searching for new molecular markers for cells obtained from abdominal aortic aneurysm
}

\author{
Marta Lesiak $^{1}$ (D) Aleksandra Augusciak-Duma ${ }^{1} \cdot$ Karolina L. Stepien $^{1} \cdot$ Agnieszka Fus-Kujawa $^{1} \cdot$ Malwina Botor $^{1}$. \\ Aleksander L. Sieron ${ }^{1}$
}

Received: 17 March 2021 / Revised: 13 May 2021 / Accepted: 19 May 2021 / Published online: 2 June 2021

(c) The Author(s) 2021

\begin{abstract}
The aim of the study was to investigate specific potential markers for cells obtained from three layers of human AAA divided into three segments along the AAA based on morphological differences. The isolated cells were compared to control commercial cell types from healthy human abdominal aortas. For each type of aortic layer, three specimens from 6 patients were compared. Total RNA was isolated from 36 cell cultures for gene expression profiling and potential new cytometry markers were typed. Isolated cells were analyzed by flow cytometry by using fluorochrome-conjugated antibodies to markers: CNN1, MYH10, ENG, ICAM2, and TEK. The relative expression of 45 genes in primary cell cultures and control lines was analyzed. Statistically significant differences were found in the expression of most of the analyzed genes between individual layers and control lines. Based on relative expression, antibodies were selected for flow cytometry. Gene expression profiles allowed to select new potential cytometry markers: CNN1, MYH10, MYOCD, ENG, ICAM2, TEK. However, none of the tested markers seems to be optimal and characteristic for a specific layer of AAA.
\end{abstract}

Keywords Abdominal aortic aneurysm (AAA) $\cdot$ Gene expression $\cdot$ Layers of AAA $\cdot$ Cytometry useful markers

\section{Introduction}

An abdominal aortic aneurysm (AAA) is a pathological dilatation of the infrarenal aorta. It develops as a result of abdominal aortic wall dilation, which might lead to blood vessel rupture very often causing the patient's death (Davis et al. 2015). AAA is a multifactorial disease and many risk factors which can lead to AAA development have been identified. The most important of them are smoking, older age, male gender (Kuivaniemi et al. 2015; Khan et al. 2015; Golledge et al. 2006), oxidative stress, and inflammation of the aortic wall (Davis et al. 2015; McCormick et al.2007), as well as hypertension and dyslipidemia (Golledge et al. 2006; Sakalihasan et al. 2018). An abdominal aortic aneurysm is the cause of death in adults as a result of aortic rupture and the only treatment for

Communicated by Michal Witt

Marta Lesiak

mlesiak@sum.edu.pl

1 Department of Molecular Biology, Faculty of Medical Sciences in Katowice, Medical University of Silesia, Medyków 18 Street, Bldg. C-1, 40-752 Katowice, Poland
AAA is open or endovascular surgical repair (Golledge 2019). Because no drug therapy is available for AAA, it is essential to understand its pathogenesis and know the specific markers involved in the development of AAA.

Anatomically normal abdominal aorta consists of three wall layers: external, middle, and internal. In the external layer, which is called tunica adventitia, fibroblasts are the main cell type (Komutrattananont et al. 2019). Fibroblasts in there produce collagen types I and III, the major components of ECM (Myllyharju and Kivirikko 2001).

Middle layer (tunica media) is mainly formed by smooth muscle cells (SMC), which maintain the vessel's structure (Komutrattananont et al. 2019; Riches et al. 2013), and regulate vascular tone and diameter through contraction by controlling blood pressure and blood flow distribution (Owens et al. 2004). In the internal layer (tunica intima), endothelial cells (EC) are the main cell type (Komutrattananont et al. 2019; Mai et al. 2013). These cells regulate tissue-fluid homeostasis, transport of nutrients, and migration of blood cells across the barrier (Komarova et al. 2017).

The process of aneurysm formation leads to apoptosis and a change in the phenotype of the cells that make up the individual layers of the aorta (Lesiak et al. unpublished work). 
Determining the phenotype of cell forming layers of the aorta and learning specific markers would allow a better understanding of the process of AAA formation. Lindquist Liljeqvist showed that in the tunica media is upregulation of gene sets related to extracellular matrix (ECM) disassembly, angiogenesis, apoptosis, complement, coagulation, and phagocytosis, as well as downregulation of those related to differentiation, development, and contraction of muscle cell, cell adhesion, and assembly of ECM and elastic fibers. The adventitia showed downregulation of gene sets associated with metal ion response, adipogenesis, and cholesterol homeostasis (Lindquist Liljeqvist et al. 2020).

Also, Ziaja D. research on the expression of cytokines in different parts of the aorta showed different intensities of the destructive process in the aortic wall in its middle part.

$\mathrm{He}$ has reported that the intensity of the destructive processes taking place in the AAA wall was in its central layer of the middle segment of AAA. His preliminary studies showed that the individual parts of the aneurysm differ in many chemical, biochemical, physical, and molecular parameters (Ziaja 2013).

Therefore, for the reported here project we hypothesized that the cells from each layer in the separate segments should differ in their gene expression patterns both between each other and control cells. Thus, the current study aimed on detecting novel molecular markers for cells obtained from different parts of AAA what should be useful for better understanding the molecular processes ongoing in AAA.

We investigated specific potential markers characteristic for cells from the layers of AAA. For this purpose, RNA isolated from AAA cells was subjected to gene expression analysis and potential markers: CNN1, MYH10, MYOCD, ENG, ICAM2, and TEK were typed for cytometry analysis.

\section{Materials and methods}

\section{Patients characteristic}

Six patients (5 men and 1 woman) with abdominal aortic aneurysm after surgical treatment were included in the study. The average age of the patients was 69.5 years (Table 1).

Exclusion of the patients from the study was based on the following criteria: (a) chronic obstructive pulmonary disease; (b) diabetes; (c) creatinine level > 1.0; (d) reconstruction of coronary vessels and thoracic aorta; (e) reconstruction of carotid artery; (f) with diagnosed generalized atherosclerosis; (g) with AAA's family history or inherited cardiovascular syndromes; (h) whom were unable to sign informed consent for surgical treatment. All surgical procedures were performed in the planned mode. Briefly, the
Table 1 Summary of patients' characteristics whom were donors of samples for cell and mRNA isolation

material was collected intraoperatively in General and Vascular Surgery Department in Katowice-Ochojec, Poland, and secured immediately in the operating room to prepare sterile $50 \mathrm{~mL}$ tubes filled with $25 \mathrm{~mL}$ of Dulbecco's Modified Eagle's Medium (Gibco, Grand Island, NY, USA) supplemented with glucose $(4.5 \mathrm{mg} / \mathrm{mL})$ (high-glucose DMEM), penicillin $(10,000 \mathrm{U} / \mathrm{ml})$, streptomycin $(10 \mathrm{mg} / \mathrm{ml})$ and amphotericin B $(25 \mu \mathrm{g} / \mathrm{ml})$ (PAA Laboratories, Pasching, Austria) and immediately delivered to the cell culture laboratory. Specifically, all treatments were started at 8:30 AM, the biopsies were taken after implantation, between 9:00 and 10:00 AM. The courier picked up the tube no later than at 11:00 AM. The sample was in the cell culture facility of the Department of Molecular Biology and Genetics, Medical University in Katowice, Poland, within the next 30 min. The research protocol was approved by the Bioethics Committee of the Silesian Medical University in Katowice, no. $\mathrm{KNW} / 0022 / \mathrm{KB} 1 / 55 / 14$ issued on June 17, 2014, and extension to $\mathrm{KNW} / 0022 / \mathrm{KB} 1 / 55 / 1 / 14 / 17$, issued on June 27, 2017 (Ziaja 2013).

\section{Isolation of cells from abdominal aortic aneurysms}

Fragments of an abdominal aortic aneurysm (AAA) around $50 \mathrm{~mm}$ long and $18 \mathrm{~mm}$ in diameter were obtained from patients following surgery. The AAAs' fragments were removed otherwise they would be discarded. Collected samples were processed immediately upon arrival to the cell culture facility. Under sterile conditions, AAA fragments were rinsed 3 times with phosphate-buffered saline (PBS) (PAA Laboratories, Pasching, Austria). The sample top end marked by the surgeon as a margin $(\sim 2 \mathrm{~mm})$ was cut out and assumed to be a control. The remaining fragment was divided into 3 equal length fragments. The divisions were reflecting the morphology of the aneurysm. In the aneurysm, the neck, aneurysm sac and its end section are distinguished. The end segment reaches, and sometimes covers, the aortic bifurcation or iliac arteries. The neck segment was defined as the upper one, 1; the aneurysm bag as 
the middle one, 2; and the end segment as the lower one, 3 (Fig. 1). All dissected fragments were subjected to incubation in the presence of dispase II (Gibco, Grand Island, NY, USA) $(2.4 \mathrm{U} / \mathrm{mL})$ in PBS for $30 \mathrm{~min}$ at $37{ }^{\circ} \mathrm{C}$. Subsequently, the longitudinal fragments were split into 3 layers of the wall: tunica intima (internal layer-IL), tunica media (middle layer-ML), and tunica adventitia (external layer-EL) (Fig. 1). Subsequently, $2 / 3$ of each layer were minced to very fine pieces and subjected to incubation in the presence of collagenase type I ( $3 \mathrm{mg} / \mathrm{mL})$ (Gibco, Grand Island, NY, USA) for $30 \mathrm{~min}$ at $37^{\circ} \mathrm{C}$. Collagenase type I was inactivated by the addition of high-glucose DMEM supplemented with $10 \%$ of fetal bovine serum (FBS) (Gibco, Grand Island, NY, USA), antibiotics and antimycotic as before. A total of 3 tissue cell cultures from each aneurysm sample were established with culture media dedicated to aortal: endothelial cells, smooth muscle cells and fibroblasts (Ziaja 2013).

A complete set of 9 samples was obtained only from patient T29 only. For the remaining patients, the samples were combined to form a total of 3 sets, respectively, for the inner, middle, and external layer of the aorta. These sets were combined and used for further analyses of gene expression. As a control, commercial cultures for each layer were used (Table 2).

\section{Cell culture}

The cells from patients' IL of AAA fragments and commercial control Human Aortic Endothelial Cells (HAEC) (Lonza, Basel, Switzerland) were cultured in EGM-2 Endothelial Medium BulletKit (Lonza, Basel, Switzerland). The cells from patients' ML of AAA fragments and commercial control human Aortic Smooth Muscle Cells (AoSMC) (Lonza, Basel, Switzerland) were cultured in SmBM-2 Smooth Muscle BulletKit (Lonza, Basel, Switzerland). The patients' EL of AAA fragments and control cells, for them Human Aortic Adventitial Fibroblasts (AoAF) (Lonza, Basel, Switzerland) were cultured in SCGM Stromal Cell BulletKit (Lonza, Basel, Switzerland). Morphology of the cells outgrown from the cultured fragments was inspected daily using an inverted contrast-phase light microscope (Olympus, T5 SN, Japan). At the beginning, the cell cultures were conducted in 6-well plates (culture surface $9.6 \mathrm{~cm}^{2} /$ well) at $37{ }^{\circ} \mathrm{C}, 95 \%$ air, and $5 \% \mathrm{CO}_{2}$. During the first 3 days of the culture, the medium was replaced with fresh every day. Upon further culture, the media were changed every other day. At $80 \%$ of confluence, the cells were transferred from each single well of 6-well plate to a $25 \mathrm{~cm}^{2}$ culture flask and again to a $75 \mathrm{~cm}^{2}$ culture flask. Subconfluent cells were subjected to freezing in liquid nitrogen until further study (Ziaja 2013).
Fig. 1 Schematic of isolation of cells specific for wall layers of AAA segments. Segments of abdominal aortic aneurysms (AAA) after fragmentation and enzyme treatment were split into 3 layers of the wall: tunica intima (internal layer-IL), tunica media (middle layerML) and tunica adventitia (external layer-EL)

\section{Fragment of abdominal aortic aneurysms (AAA) Љ}

Fragmentation<smiles>[10BH]</smiles>

control upper/neck-1 middle/aneurysm sac-2 lower/end-3

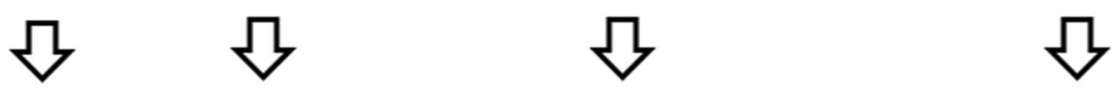

Dispase treatment to separate layers of AAA segments

\begin{tabular}{|l|l|l|l|}
\hline \multicolumn{5}{|c|}{ Separated layers of the AAA segments } \\
\hline Internal (ILC) & Internal (IL1) & Internal (IL2) & Internal (IL3) \\
\hline Middle (MLC) & Middle (ML1) & Middle (ML2) & Middle (ML3) \\
\hline External (ELC) & External (EL1) & External (EL2) & External (EL3) \\
\hline
\end{tabular}

Collagenase treatment to release cells during tissue cultures 
Table 2 Summary of the layers and patients

\begin{tabular}{|c|c|c|c|c|c|c|c|c|c|}
\hline \multirow[t]{4}{*}{ Patient no } & \multicolumn{3}{|c|}{ Internal layer (IL) } & \multicolumn{3}{|c|}{ Middle layer (ML) } & \multicolumn{3}{|c|}{ External layer (EL) } \\
\hline & \multicolumn{3}{|c|}{ Tunica intima } & \multicolumn{3}{|c|}{ Tunica media } & \multicolumn{3}{|c|}{ Tunica adventitia } \\
\hline & \multicolumn{3}{|c|}{ Vertical segments } & \multicolumn{3}{|c|}{ Vertical segments } & \multicolumn{3}{|c|}{ Vertical segments } \\
\hline & IL1 & IL2 & IL3 & ML1 & ML2 & ML3 & EL1 & EL2 & EL3 \\
\hline $\mathrm{T} 14$ & $\mathrm{x}$ & $\mathrm{x}$ & $\mathrm{x}$ & $\mathrm{x}$ & $\mathrm{x}$ & $\mathrm{x}$ & & & \\
\hline T15 & & & & & & & & $\mathrm{x}$ & $\mathrm{x}$ \\
\hline $\mathrm{T} 20$ & & & & $\mathrm{x}$ & $\mathrm{x}$ & $\mathrm{x}$ & $\mathrm{x}$ & & \\
\hline $\mathrm{T} 23$ & $\mathrm{x}$ & $\mathrm{x}$ & $\mathrm{x}$ & & & & & & \\
\hline $\mathrm{T} 25$ & & & & & & & $\mathrm{x}$ & $\mathrm{x}$ & $\mathrm{x}$ \\
\hline $\mathrm{T} 29$ & $\mathrm{x}$ & $\mathrm{x}$ & $\mathrm{x}$ & $\mathrm{x}$ & $\mathrm{x}$ & $\mathrm{x}$ & $\mathrm{x}$ & $\mathrm{x}$ & $\mathrm{x}$ \\
\hline HAEC & $\mathrm{x}$ & $\mathrm{x}$ & $\mathrm{x}$ & & & & & & \\
\hline AoSMC & & & & $\mathrm{x}$ & $\mathrm{x}$ & $\mathrm{x}$ & & & \\
\hline AoAF & & & & & & & $\mathrm{x}$ & $\mathrm{x}$ & $\mathrm{x}$ \\
\hline
\end{tabular}

$x$ represents the material taken from a particular layer of the patient for analysis of gene expression.

\section{RNA analysis}

Total RNA was isolated from cell culture by Zymogen Quick RNA Mini Prep (Ambion, Austin, Texas, USA). Quality and quantity evaluation was performed using a NanoDrop 2000 spectrophotometer (Thermo Fisher Scientific, Waltham, Massachusetts, U.S.A.). Total RNA (1 to $2 \mu \mathrm{g}$ ) was transcribed using a cDNA Transcriptor First Strand cDNA Synthesis Kit (Roche, Penzberg, Upper Bavaria, Germany) using random hexamers. Expression analyses with Real Time Custom Panel 384-96 (config. no 100142046; Roche) and LightCycler480 Probe Master (Roche) were performed using LightCycler480 II (Roche). The genes analyzed in this report are listed in Supplement Table 1

Total RNA of quality and at the amount required for gene expression profiling was successfully isolated from 36 cell cultures. The characteristics of the patients whose samples were used for further gene expression analysis (gender, age) are summarized in Table 1.

For each layer of the aneurysm, tissue cell cultures derived from 3 patients and from standard commercial culture for each layer were analyzed by the gene expression (Table 2) and from standard commercial culture for each layer.

\section{Gene expression profiling}

The gene expression was analyzed using GenEx ver6 software. Raw data were subjected to normalization to the sample number followed by normalization to reference genesGAPDH, PPIA, and RPL0 (Supplement Table 1). The last preprocessing step was filling the missing data with 0 , and relative quantification was performed using the comparative threshold $(\mathrm{Ct})$ method $(\Delta \Delta \mathrm{Ct})$, where the relative gene expression level equals to $2^{-\Delta \Delta C t}$.

\section{Fluorescence assisted cell flow cytometry analyses}

The cells from a specific aorta layer were analyzed by using Facs Aria I instrument (Becton Dickinson, Franklin Lakes, New Jersey, USA). Fluorochrome-conjugated specific antibodies directed against a particular surface or cytoplasmic antigen were used. The cells obtained of the three layers from each segment of the aneurysm and expanded in culture were recovered following incubation with Accutase Cell Detachment Solution (Becton Dickinson, Franklin Lakes, New Jersey, USA) by centrifugation at $159 \times g$ for $5 \mathrm{~min}$. The samples were washed twice with PBS (PAA Laboratories, Pasching, Austria), resuspended, and counted with the use of a cell counter (Bio Rad, Hercules, California, USA). After a final collection of the cells by centrifugation before they were washed in Flow Cytometry Staining Buffer (R\&D Systems, Minneapolis, MN, USA) and resuspended to a final cell density of $10^{6}$ cells/200 $\mu$ l. Fluorochrome-conjugated antibodies against surface antigens were added for detection of ENG (CD105) (Exbio, Praha, Czech Republic), ICAM2 (CD102) (Exbio, Praha, Czech Republic) and TEK (CD202b) (BioLegend, San Diego, USA). After 30 min of incubation with the appropriate antibody at room temperature, the cells were centrifuged as before. To remove the excess of antibodies following staining, $2 \mathrm{~mL}$ of Flow Cytometry Staining Buffer (R\&D Systems, Minneapolis, MN, USA) was added. The cells were centrifuged again and resuspended to a final cell density of $10^{6}$ cells in $400 \mu \mathrm{l}$ of Flow Cytometry Staining Buffer (R\&D Systems, Minneapolis, MN, USA) and analyzed with the use of Facs Aria I. AoAF cells were used as a positive control cell for the cells obtained from EL. HAEC cells were used as a positive control for the cells obtained from IL. The negative control cells without treatment were used to set the scale. 
Fluorochrome-conjugated antibodies against cytoplasmic antigens were added for detection of MYH10 (Santa Cruz Biotechology, Inc., Heidelberg, Germany) and CNN1 (calponin 1 antibody) (Novusbio, Minneapolis, USA). Respectively, after recovery of the cells from the culture as already described the cells were washed twice with PBS (PAA Laboratories, Pasching, Austria) and centrifuged as before. The cells were counted with the use of a cell counter. Following centrifugation, the cells were resuspended in Flow Cytometry Fixation/Permeabilization Buffer I (R\&D Systems, Minneapolis, MN, USA) and incubated at $2-8{ }^{\circ} \mathrm{C}$ for $30 \mathrm{~min}$. After incubation, the cells were centrifuged at $587 \times g$ for $5 \mathrm{~min}$ and resuspended to a final density of $10^{6}$ cells in $200 \mu \mathrm{l}$ of Flow Cytometry Permeabilization/Wash Buffer I (cat. no. FC005, R\&D Systems, Minneapolis, MN, USA). Fluorochrome-conjugated antibodies against cytoplasmic antigens were added to the cell suspension and incubated for $40 \mathrm{~min}$ in a covered ice bucket. To wash off excess antibodies following staining, $2 \mathrm{~mL}$ of Flow Cytometry Permeabilization/Wash Buffer I (R\&D Systems, Minneapolis, MN, USA) was added. The cells were centrifuged for $5 \mathrm{~min}$ at $587 \times g$, resuspended in $400 \mu \mathrm{l}$ of Flow Cytometry Staining Buffer-FC001 (R\&D Systems, Minneapolis, MN, USA) and analyzed using FACS Aria I instrument. AoSMC cells were used as a control to the cells obtained from ML. The negative control cells without treatment were used to set the scale.

\section{Statistical analyses}

Kolmogorov-Smirnov test was employed to determine if the data from the population showed a normal distribution. For data with normal distribution, the $T$-test 1 -tail was engaged in analysis of the data. For the data that were not normally distributed, a nonparametric test (Mann-Whitney 1-tailed test) was used for analysis of the data. The threshold for $p$-value was set less than 0.05 .

\section{Results}

\section{Relative expression in standard cell cultures}

We analyzed the relative expression of marker genes in cultured cells assumed as standard cells (HAEC for endothelial cells in the internal layer-IL; AoSMC for smooth muscle cells in middle layer-ML; and AoAF for fibroblasts in the external layer EL). The most important factors for accepting the gene as a potential marker for cells were the significant differences in expression between standard cells for each layer (Supplement Tables 2 and 3). From this step, we focused on the ALCAM, CD40, CNN1, KRT18, KRT8, MYH10, MYOCD, ENG, TEK, CD34,
CD70, CD90, CDH5, IL1R2, PECAM1, and S100A4 (Supplement Tables 2, 3, 4, 5).

(Supplement Tables 2. $T$-test $p$-values, Supplement Table 3. Mann-Whitney $p$-values, Supplement Table 4. Fold change differences between layers of AAA, Supplement Table 5. Relative expression of analyzed genes).

\section{Relative expression in primary cell cultures}

The second stage in determining a potential marker was to analyze whether primary cultures derived from specific AAA layers gave the higher gene expression than in standard cultures, since the expression of potential markers in the primary cultures should be lower. For the internal layer, these genes are ACTA1, ANGPTL4, CD209, CD68, CD83, CD90/THY1, DDR2, ITGA1, NOS3, S100A4SELP, and $S M T N$. For the middle layer, these genes are ANGPTL4, CD34, CD83, ICAM2, S100A4, SELP, and VWF. And for the external layer: ANGPTL4, C5AR1, CD163, CD1D, CD40, CD69, CD90/THY1, CSF1R, EPCAM, ICAM2, KRT18, KRT8, MYOCD, PECAM1, S1OOA4, TNFRSF8.

The third step was to determine whether the expression of a particular potential new marker was consistent across specific layers in the three segments of AAA. Based on the gene expression, it is not possible to distinguish different cells based on a single gene because we observed the expression of all genes in all primary cell lines. Only in standard cell culture we observed the lack of expression of nine genes. MYOCD, CD86, CD163, IL1R2, and IL2RA were not expressed in HAEC. There was no SMTN, NOS3, CD209, $I L 2 R A$ expression in the AoAF culture. And in the AoSMC culture, we observed the lack of NOS3, CD1A,CD86, and IL2RA.

From these analyses, we suggested six potential new cytometry marker genes encoding: CNN1, MYH10, MYOCD, ENG, ICAM2 and TEK (Fig. 2). Since it was not possible to obtain antibodies for MYOCD cytometry measurements, only five proteins were analyzed.

\section{Phenotypic analysis of cells isolated from the layers of AAA longitudinal fragments using flow cytometry}

Analysis of the flow cytometry data of cells obtained from AAA ILs revealed that these cells were positive for ENG, TEK, and CNN1 in comparison to control endothelial cells from the aortic wall which were positive for ENG, ICAM2, TEK and CNN1. In the control, cells with IL of the aortic wall of the AAA were $44.7 \%$ of cells with ENG, $50.2 \%$ cells with ICAM2, $5.7 \%$ of cells with TEK and $5.6 \%$ cells with CNN1. In cells isolated from ILs, $18.97 \%$, $19.23 \%$, and $20.8 \%$ of fragments 1,2 , and 3 were positive for ENG. Moreover, a small number of cells were positive for TEK and $4.33 \%, 3.87 \%$, and $1.13 \%$ did have that 


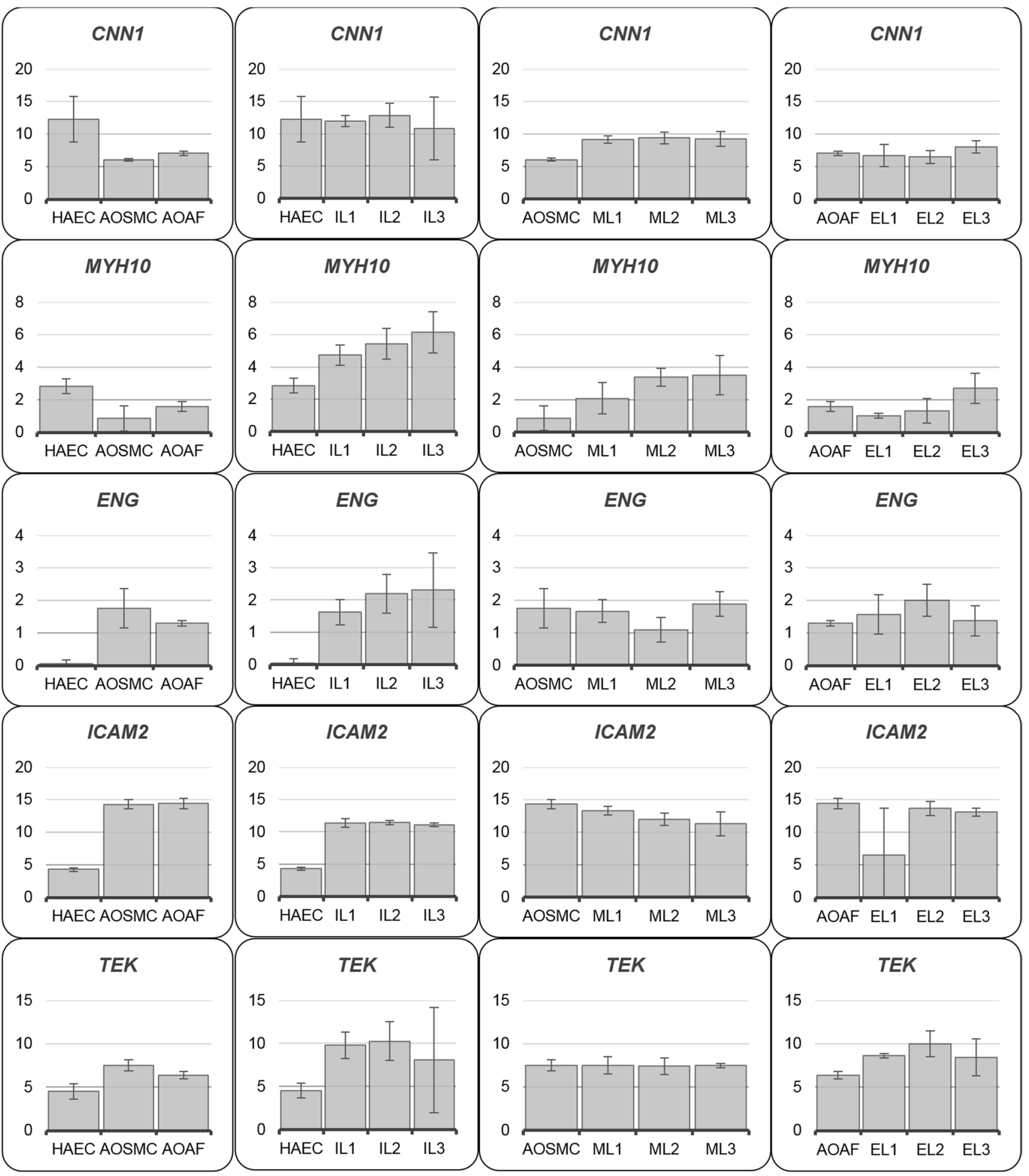

Fig. 2 Relative expression of potential new markers. $Y$ axis represents relative expression $\mathrm{Nrel}=2^{\wedge}(\Delta C$ normalized target $-\Delta C$ control $)$, axis $X$ represents expression of genes in particular cell lines

marker in fragments 1,2, and 3. Analyses obtained also that cells isolated from ILs were positive for CNN1 and $7.07 \%, 2.87 \%$, and $5.53 \%$ of fragments 1,2 , and 3 were positive for CNN1 (Fig. 3).
The cells obtained from AAA MLs were positive as expected for CNN1, but also for ENG and in small numbers for TEK. In these cells, $6.37 \%, 13.93 \%$, and $3.5 \%$ were positive for $\mathrm{CNN} 1$ in the fragments 1,2, and 3. Many more 


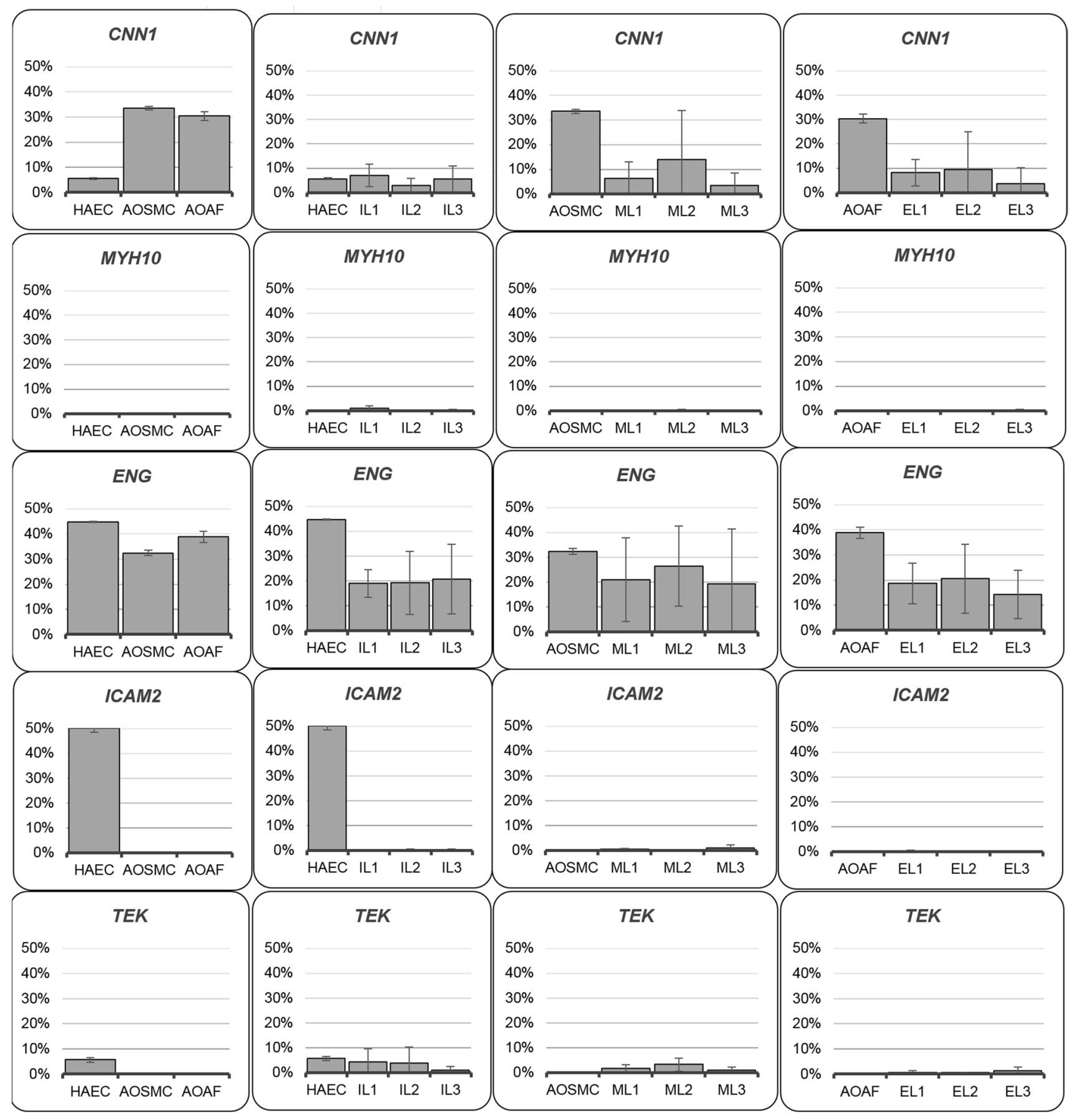

Fig. 3 Phenotypic analysis of cells by flow cytometry. Number of positive cells for the tested marker expressed in \%

cells were positive for ENG and it was $20.97 \%, 26.53 \%$, and $19.37 \%$ in fragments 1,2 , and 3.

Only a small number of cells obtained from ML of the aortic wall did have the marker TEK and it was $1.73 \%, 3.3 \%$, and $1.03 \%$ in fragments 1,2 , and 3 .

In the control, cells in ML of the aortic wall of the AAA were $33.5 \%$ of cells with CNN1 and $32.4 \%$ cells with ENG (Fig. 3).
Cells isolated from EL of the aortic wall of the AAA, as expected, did not have detectable markers ICAM 2 and TEK that are characteristic for cells in the IL of the aortic wall. Moreover, they were negative for MYH10. Instead, some $8.17 \%, 9.53 \%$, and $3.7 \%$ of these cells were positive for CNN1 in fragments 1, 2, and 3. Many more cells were positive for ENG and it was $18.67 \%, 20.57 \%$, and $14.3 \%$ in fragments 1, 2, and 3. In the control, cells with EL of the 
aortic wall of the AAA were $30.4 \%$ of cells with CNN1 and 38.8\% cells with ENG (Fig. 3).

\section{Discussion}

In our research, we tried to select a specific marker for cells isolated from AAA layers. As of today, there is no specific biomarker for AAA development, and molecular analysis of the affected tissue often yields conflicting results. The complex mechanisms involved in the development of aneurysms need to be investigated, but tools are lacking, or rather there are a large number of proteins that are being analyzed in experiments in the scientific and medical world. For this reason, it does not allow the results to be easily compared with the literature. Any attempt to slow the development of AAA or even heal the affected tissue must be tested not only in animal models but also in cultured cells. Obtaining primary cultures from AAA tissue is a complex and difficult task, and as a result, scientists are provided with a mixture of cells that must be identified and maintained in cell culture over a period of time (Lesiak et al. unpublished work; Ziaja 2013). The analysis of these cells without proper identification is futile. Based on the analysis of gene expression, we selected potential new cytometric markers: CNN1, MYH10, ENG, ICAM2 and TEK. We wanted to investigate one of them, which could be a specific marker for one of the AAA layers and could be useful for distinguishing cells from it.

The process of AAA formation is characterized by a change in the phenotype of cells building individual layers of the aortic wall (Lesiak et al. unpublished work). In the process of AAA formation, a change in cell phenotype (Ailawadi et al. 2009; Yuan and Wu 2018), cell apoptosis (Golledge 2019), as well as different expression of genes associated with ECM degradation have been noticed (Farrell et al. 2019; Kobayashi et al. 2002; Armstrong et al. 2002; Quintana and Taylor 2019).

Ailawadi examined the expression of smooth muscle cell marker genes, including SM22A, $\alpha$-SMA, MMP-2, and MMP-9 in abdominal aneurysm tissue in comparison to control tissue (Ailawadi et al. 2009). He demonstrated a decrease in SM marker genes, which was explained by SMC apoptosis and by changes in SMC phenotype in response to changing of surrounding environment (Ailawadi et al. 2009). Lack of $\alpha$-SMA positive cells in the middle layer of the aortic wall in patients with AAA was observed in comparison to control cells of aorta (Lesiak et al. unpublished work). $\alpha$-SMA expressions in aortic smooth muscle cells of patients with AAA were significantly reduced (Yuan and $\mathrm{Wu} 2018$ ).

CNN1 is a regulator of smooth muscle contractility and responsiveness to contractile activation (Liu and Jin 2016). It is an actin filament associated regulatory protein, expressed both in smooth muscle and in many nonmuscle cells (Liu and Jin 2016). In our study, the number of CNN1 positive cells was also reduced in all layers of the aorta compared to control cells. In contrast, CNN1 gene expression was surprisingly highest in HAEC control cells (difference in fold change: 74 in AoSMC and 36 in AoAF) and in inner layer cells from AAA patients. We expected it to be the highest in the middle layer (Hadi et al. 2018). The discrepancy may be due to $2 \mathrm{D}$ culture as this protein is involved in the regulation of the microenvironment and interaction within the ECM (Birgersdotter et al. 2005; Dozio et al. 2019).

MYH10 is one of the isoforms of nonmuscle myosin II B. It is involved in cell shape determination, cytokinesis, remodeling of the ECM, and formation of cell-cell adhesion (Heissler and Manstein 2013). MYH10 is commonly referred to as a marker of aortic smooth muscle cells and tunica intima (Wang et al. 2018). Analysis of mRNA expression in our study did not confirm this. In our study, MYH10 gene expression was the highest in HAEC compared to other control cells. MYH10 gene expression was also highest in cells from internal AAA layers. Nonmuscle myosin IIB has a significant effect on the maintenance of the cell-cell junction and is also a negative regulator of self-renewal of pluripotent stem cells (Walker et al. 2010; Newell-Litwa et al. 2015). It is therefore not surprising that the inner layer has a large amount of mRNA for this protein. It was unexpected that flow cytometric analyses did not show positive results for MYH10 cells in all layers.

Endoglin is a $180 \mathrm{kDa}$ type I transmembrane glycoprotein and functions as a receptor for the ligand of the TGF- $\beta$ superfamily (Schoonderwoerd et al. 2010). Endoglins regulate proliferation (Lebrin et al. 2004) and migration (Bautch 2017) of endothelial cells. More recent work has shown endoglin expression on a variety of cell (Schoonderwoerd et al. 2010). In our study, all cells tested were positive for ENG, although HAEC expression was very low (relative expression $=0.05$ ). It shows that although endoglin is widely described as an endothelial marker, it is not a strong enough indicator. Moreover, the primary cell lines obtained from the inner layer have the highest gene expression compared to the control HAEC endothelial cells and other cell lines.

Intercellular adhesion molecule 2 (ICAM-2 belongs to the immunoglobulin (Ig) superfamily, constitutively expressed in endothelial junction (McLaughlin et al. 1998). ICAM-2 is concentrated at endothelial cell-cell contact (Huang et al. 2005). Several studies have shown that ICAM-2 expression on endothelial cells is concentrated at the junctions and is involved in leukocyte recruitment and angiogenesis, and is responsible for the regulation of endothelial barrier function and permeability (Huang et al. 2005; Amsellem et al. 2014). There are numerous reports of the use of ICAM2 as an endothelial surface marker (Gao et al. 2017; Sadek 
et al. 2008), which is upregulated during differentiation into mature vascular endothelial cells. ICAM-2 is also an activator of the PI3/AKT pathway leading to inhibition of apoptosis (Perez et al. 2002). Our flow cytometry analyses revealed that ICAM2 positive cells were the only control endothelial cells. Among the cells isolated from the internal layer, there were no ICAM2 positive cells. Lack of this marker indicated that there was a significant loss of endothelial cells in the internal layer of the aortic wall in comparison to control cells. Surprising was the fact that ICAM2 gene expression was the lowest in control endothelial cells HAEC in comparison to other cells (1038 and 1135 of fold change difference between the expression of HAEC in AoSMC and AoAF cells).

TEK (TIE2) is an angiopoietin receptor tyrosine kinase expressed in endothelial cells and their precursors. There is restriction in the distribution of TEK to the vascular endothelium (Sato et al. 1995; Dumont et al. 1994). TEK is inactivated during the process of angiogenesis and inflammation, which leads to neovascularization of the abdominal aortic aneurysm and increased infiltration of monocytes/ macrophages (Yu et al. 2016).

Our study showed that TEK positive cells in control cell lines were observed only in HAEC. There was a lack of this marker in the cells from the external layer. There were some TEK positive cells in the internal and external layer of AAA. The highest expression of TEK gene was observed in AoSMC. There was no difference in expression in AoSMC and AAA mid-tier cell lines. Increased expression of TEK was observed in cell lines obtained from the inner layers of aneurysm compared to the standard HAEC line. Selection of a specific marker of cells isolated from layers of AAA could provide information about the mechanism of AAA formation. Unfortunately, none of the tested markers seems to be optimal and characteristic for a specific layer of AAA. This study showed that only ICAM 2 was present only on the surface of HAEC cells. Its absence on the surface of cells from the inner AAA layer may indicate a change in the phenotype of these cells. Absence of ICAM2 on the surface of other control cells, as well as on the surface of cells from the middle and external layers would be desirable. However, this conflicts with the ICAM2 gene expression in all types of cells from all layers. CNN1, MYH10, and MYOCD were intended to be surface markers of SMC. At the mRNA level, there were differences between standard cell lines. Unfortunately, these differences did not translate into cell lines obtained from individual layers of the abdominal aortic aneurysm and proteins. Analysis of the expression of protein markers for specific cell lines is not enough. All proteins analyzed were intended to be cell-specific markers. Current molecular techniques for mRNA or protein analysis are very sensitive. Cells are living organisms that produce all kinds of mRNA and proteins in small amounts. The increasing sensitivity of molecular techniques makes the analysis cumbersome as increasing data can be obtained. The time lag between mRNA and protein expression may also explain the observed differences between expression analysis and flow cytometry.

Supplementary Information The online version contains supplementary material available at https://doi.org/10.1007/s13353-021-00641-4.

Acknowledgements The authors would like to acknowledge Prof. Krzysztof Ziaja and Prof Wacław Kuczmik from the Department of General and Vascular Surgery, Medical University of Silesia, Katowice, Poland, for constructive medical consultation of the manuscript and granting the tissues of abdominal aortic aneurysm.

Author contribution All authors contributed to the study conception and design. Material preparation, data collection, and analysis were performed by Marta Lesiak Aleksandra Auguściak-Duma, Karolina L. Stepien, Agnieszka Fus-Kujawa, Malwina Botor, and Aleksander L. Sieron.

The first draft of the manuscript was written by Marta Lesiak and all authors commented on previous versions of the manuscript. All authors read and approved the final manuscript.

Funding This work was supported by the Institutional grant (KNW$1-055 / \mathrm{K} / 8 / \mathrm{O}$ ). The equipment for molecular analyses used in this work was purchased from the Silesian Bio-Farma Center for Biotechnology, Bioengineering and Bioinformatics. Project (no POIG.02.01.00-00166/08, THE OPERATIONAL PROGRAMME INNOVATIVE ECONOMY FOR 2007-2013. Priority Axis 2) (awarded to ALS). https:// www.poig.2007-2013.gov.pl, the funders had no role in study design, data collection and analysis, decision to publish, or preparation of the manuscript.

Data availability All data generated or analyzed during this study are included in this published article.

Code availability Not applicable.

\section{Declarations}

Ethics approval and consent to participate The study and research protocol were approved by the Bioethics Committee of Silesian Medical University in Katowice (no. KNW/0022/KB1/55/14 issued on 17 June 2014, and extension no. KNW/0022/KB1/55/1/14/17, issued on 27 June 2017). Written informed consent was obtained from each patient.

Consent for publication Not applicable.

Conflict of interest The authors declare no competing interests.

Open Access This article is licensed under a Creative Commons Attribution 4.0 International License, which permits use, sharing, adaptation, distribution and reproduction in any medium or format, as long as you give appropriate credit to the original author(s) and the source, provide a link to the Creative Commons licence, and indicate if changes were made. The images or other third party material in this article are included in the article's Creative Commons licence, unless indicated otherwise in a credit line to the material. If material is not included in the article's Creative Commons licence and your intended use is not permitted by statutory regulation or exceeds the permitted use, you will 
need to obtain permission directly from the copyright holder. To view a copy of this licence, visit http://creativecommons.org/licenses/by/4.0/.

\section{References}

Ailawadi G, Moehle CW, Pei H et al (2009) Smooth muscle phenotypic modulation is an early event in aortic aneurysms. J Thorac Cardiovasc Surg 138:1392-1399. https://doi.org/10.1016/j.jtcvs. 2009.07.075

Amsellem V, Dryden NH, Martinelli R et al (2014) ICAM-2 regulates vascular permeability and $\mathrm{N}$-cadherin localization through ezrin-radixin-moesin (ERM) proteins and Rac-1 signalling. Cell Commun Signal 12:12. https://doi.org/10.1186/1478-811X-12-12

Armstrong PJ, Johanning JM, Calton WC Jr et al (2002) Differential gene expression in human abdominal aorta: aneurysmal versus occlusive disease. J Vasc Surg 35:346-414. https://doi.org/10. 1067/mva.2002.121071

Bautch VL (2017) Endoglin moves and shapes endothelial cells. Nat Cell Biol 19:593-595. https://doi.org/10.1038/ncb3543

Birgersdotter A, Sandberg R, Ernberg I (2005) Gene expression perturbation in vitro-a growing case for three-dimensional (3D) culture systems. Semin Cancer Biol 15:405-412. https://doi. org/10.1016/j.semcancer.2005.06.009

Davis FM, Rateri DL, Daugherty A (2015) Abdominal aortic aneurysm: novel mechanisms and therapies. Curr Opin Cardiol 30:566-573. https://doi.org/10.1097/HCO.0000000000000216

Dozio SM, Montesi M, Campodoni E et al (2019) Differences in osteogenic induction of human mesenchymal stem cells between a tailored 3D hybrid scaffold and a 2D standard culture. J Mater Sci Mater Med 30:1-12. https://doi.org/10.1007/ s10856-019-6346-3

Dumont DJ, Gradwohl G, Fong GH et al (1994) Dominant-negative and targeted null mutations in the endothelial receptor tyrosine kinase, tek, reveal a critical role in vasculogenesis of the embryo. Genes Dev 8:1897-1909. https://doi.org/10.1101/gad.8.16.1897

Farrell K, Simmers P, Mahajan G et al (2019) Alterations in phenotype and gene expression of adult human aneurysmal smooth muscle cells by exogenous nitric oxide. Exp Cell Res 384:111589. https:// doi.org/10.1016/j.yexcr.2019.111589

Gao LP, Du MJ, Lv JJ et al (2017) Use of human aortic extracellular matrix as a scaffold for construction of a patient-specific tissue engineered vascular patch. Biomed Mater 12:065006. https://doi. org/10.1088/1748-605X/aa801b

Golledge J (2019) Abdominal aortic aneurysm: update on pathogenesis and medical treatments. Nat Rev Cardiol 16:225-242. https://doi. org/10.1038/s41569-018-0114-9

Golledge J, Muller J, Daugherty A, Norman P (2006) Abdominal aortic aneurysm. Arterioscler Thromb Vasc Biol 26:2605-2613. https:// doi.org/10.1161/01.ATV.0000245819.32762.cb

Hadi T, Boytard L, Silvestro M et al (2018) Macrophage-derived netrin-1 promotes abdominal aortic aneurysm formation by activating MMP3 in vascular smooth muscle cells. Nat Commun 9:5022. https://doi.org/10.1038/s41467-018-07495-1

Heissler SM, Manstein DJ (2013) Nonmuscle myosin-2: mix and match. Cell Mol Life Sci 70:1-21. https://doi.org/10.1007/ s00018-012-1002-9

Huang MT, Mason JC, Birdsey GM et al (2005) Endothelial intercellular adhesion molecule (ICAM)-2 regulates angiogenesis. Blood 106:1636-1643. https://doi.org/10.1182/blood-2004-12-4716
Khan S, Verma V, Verma S, Polzer S, Jha S (2015) Assessing the potential risk of rupture of abdominal aortic aneurysms. Clin Radiol 70:11-20. https://doi.org/10.1016/j.crad.2014.09.016

Kobayashi M, Matsubara J, Matsushita M et al (2002) Expression of angiogenesis and angiogenic factors in human aortic vascular disease. J Surg Res 106:239-245. https://doi.org/10.1006/jsre. 2002.6468

Komarova YA, Kruse K, Mehta D, Malik AB (2017) Protein interactions at endothelial junctions and signaling mechanisms regulating endothelial permeability. Circ Res 120:179-206. https://doi.org/ 10.1161/CIRCRESAHA.116.306534

Komutrattananont P, Mahakkanukrauh P, Das S (2019) Morphology of the human aorta and age-related changes: anatomical facts. Anat Cell Biol 52:109-114. https://doi.org/10.5115/acb.2019.52.2.109

Kuivaniemi H, Ryer EJ, Elmore JR, Tromp G (2015) Understanding the pathogenesis of abdominal aortic aneurysms. Expert Rev Cardiovasc Ther 13:975-987. https://doi.org/10.1586/14779072. 2015.1074861

Lebrin F, Goumans MJ, Jonker L et al (2004) Endoglin promotes endothelial cell proliferation and TGF- $\beta /$ ALK1 signal transduction. EMBO J 23:4018-4028. https://doi.org/10.1038/sj.emboj. 7600386

Lindquist Liljeqvist M, Hultgren R et al (2020) Tunica-specific transcriptome of abdominal aortic aneurysm and the effect of intraluminal thrombus, smoking, and diameter growth rate. Arterioscler Thromb Vasc Biol 40:2700-2713. https://doi.org/10.1161/ ATVBAHA.120.314264

Liu R, Jin JP (2016) Calponin isoforms CNN1, CNN2 and CNN3: regulators for actin cytoskeleton functions in smooth muscle and non-muscle cells. Gene 585:143-153. https://doi.org/10.1016/j. gene.2016.02.040

Mai J, Virtue A, Shen J, Wang H, Yang XF (2013) An evolving new paradigm: endothelial cells-conditional innate immune cells. J Hematol Oncol 6:61. https://doi.org/10.1186/1756-8722-6-61

McCormick ML, Gavrila D, Weintraub NL (2007) Role of oxidative stress in the pathogenesis of abdominal aortic aneurysms. Arterioscler Thromb Vasc Biol 27:461-469. https://doi.org/10.1161/ 01.ATV.0000257552.94483.14

Mclaughlin F, Hayes BP, Horgan CM et al (1998) Tumor necrosis factor (TNF)- $\alpha$ and interleukin (IL)- $1 \beta$ down-regulate intercellular adhesion molecule (ICAM)-2 expression on the endothelium. Cell Adhes Commun 6:381-400. https://doi.org/10.3109/1541906980 9109147

Myllyharju J, Kivirikko KI (2001) Collagen and collagen-related diseases. Ann Med 33:7-21. https://doi.org/10.3109/0785389010 9002055

Newell-Litwa KA, Horwitz R, Lamers ML (2015) Non-Muscle myosin II in disease: mechanisms and therapeutic opportunities. Dis Model Mech 8:1495-1515. https://doi.org/10.1242/dmm.022103

Owens GK, Kumar MS, Wamhoff BR (2004) Molecular regulation of vascular smooth muscle cell differentiation in development and disease. Physiol Rev 84:767-801. https://doi.org/10.1152/physr ev.00041.2003

Perez OD, Kinoshita S, Hitoshi Y et al (2002) Activation of the PKB/ AKT pathway by ICAM-2. Immunity 16:51-65. https://doi.org/ 10.1016/s1074-7613(02)00266-2

Quintana RA, Taylor WR (2019) Cellular mechanisms of aortic aneurysm formation. Circ Res 124:607-618. https://doi.org/10.1161/ CIRCRESAHA.118.313187

Riches K, Angelini TG, Mudhar G et al (2013) Exploring smooth muscle phenotype and function in a bioreactor model of abdominal aortic aneurysm. J Transl Med 11(12):208. https://doi.org/10. 1186/1479-5876-11-208 
Sadek M, Hynecek RL, Goldenberg S et al (2008) Gene expression analysis of a porcine native abdominal aortic aneurysm model. Surgery 144:252-258. https://doi.org/10.1016/j.surg.2008.04.007

Sakalihasan N, Michel JB, Katsargyris A et al (2018) Abdominal aortic aneurysms. Nat Rev Dis Primers 4:34. https://doi.org/10.1038/ s41572-018-0030-7

Sato TN, Tozawa Y, Deutsch U et al (1995) Distinct roles of the receptor tyrosine kinases Tie-1 and Tie-2 in blood vessel formation. Nature 376:70-74. https://doi.org/10.1038/376070a0

Schoonderwoerd MJA, Goumans MJTH, Hawinkels LJAC (2010) Endoglin: beyond the endothelium. Biomolecules 10:289. https:// doi.org/10.3390/biom10020289

Walker A, Su H, Conti MA et al (2010) Non-muscle myosin II regulates survival threshold of pluripotent stem cells. Nat Commun 1:71. https://doi.org/10.1038/ncomms1074

Wang K, Zhou Y, Li G et al (2018) MMP8 and MMP9 gene polymorphisms were associated with breast cancer risk in a Chinese Han population. Sci Rep 8:13422. https://doi.org/10.1038/ s41598-018-31664-3

Yu H, Moran CS, Trollope AF et al (2016) Angiopoietin-2 attenuates angiotensin II-induced aortic aneurysm and atherosclerosis in apolipoprotein E-deficient mice. Sci Rep 6:35190. https://doi. org/10.1038/srep35190

Yuan SM, Wu N (2018) Aortic $\alpha$-smooth muscle actin expressions in aortic disorders and coronary artery disease: an immunohistochemical study. Anatol J Cardiol 19:11-16. https://doi.org/10. 14744/AnatolJCardiol.2017.7839

Ziaja D (2013) Drożność tętnicy krezkowej dolnej, odwarstwienie skrzepliny oraz rozległość tętniaka jako kliniczny marker nasilenia zapalenia i ekspresji cytokin, protein adaptorowych oraz zawartość metali i niemetali w ścianie podnerkowego tętniaka aorty brzusznej. PhD Thesis, Medical University of Silesia, Poland

Publisher's note Springer Nature remains neutral with regard to jurisdictional claims in published maps and institutional affiliations. 